\title{
JUURNAL.RU
}

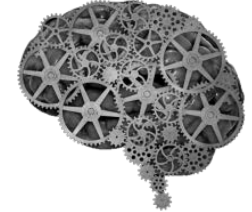

COMPANY GROUP "INTELLEKT"

Кузина Н.В. «Российский научно-исследовательский институт культурного и природного наследия имени Д.С.Лихачева»

Москва, Россия

doi: 10.18411/lj2016-3-18

\section{Об экспериментальном этапе разработки методики выявления личного набора микрострессоров и психолингвистической экспертизы}

C XIX века существует ряд концепций, объясняющих взаимосвязь функционирования второй сигнальной системы, личностных особенностей, наличия стрессирующих ситуаций и возникновения психосоматических заболеваний как одного из типов трансформации воздействия стрессирующего фактора и срабатывания механизма защиты. Согласно концепции Ф.Данбар, могут быть выделены и описаны специфические личностные типажи, связанные с предрасположенностью к патологии (коронарный, гипертонический, аллергический, склонный к повреждению). Описаны акцентуации («психиатрическая версия» по П.Б.Ганнушкину, А.Е.Личко и др. [2]), способствующие возникновению психопатологий.

Опыт (память) складывается стихийно и представляет собой набор фреймов (М.Л.Минский), пропозиций, четырехкортежностей (Р.Бэндлер, Дж.Гриндер), инграмм (Л.Р.Хаббард), синкретов (Л.С.Выготский, А.Р.Лурия). Ситуация удовольствия и неудовольствия, вызвавшая наибольшие эпизодические функциональные отклонения показателей гомеостаза, помечается содержимым терминального слота (синкрета). Одним из главных способов фиксации данных ситуаций является «речевая память», в психолингвистике характеризующаяся разновидностями: а) «память ситуации», 
позволяющая однозначно реагировать на повторение одного и того же (полностью или частично) набора обусловливающих речевое высказывание внешних факторов; б) сохранение каких-то компонентов данного высказывания в памяти на время осуществления этого высказывания, в) запоминание и воспроизведение плана высказывания или его программы; г) запоминание и воспроизведение содержания высказывания; д) запоминание и воспроизведение формы высказывания, вернее, выучивание и воспроизведение его «наизусть»; е) запоминание и воспроизведение грамматических структур; ж) запоминание и воспроизведение слов; з) запоминание и воспроизведение речевых шаблонов; и) и, наконец, запоминание и воспроизведение звуковых последовательностей» [3].

В психологии, социологии, психолингвистике существуют исследования репертуарной решетки личности, индивидуального ассоциативного словаря [5, 8, 9]. Установлена взаимосвязь между психофизиологическим состоянием респондента и спецификой его эмоциональных реакций на вербальные стимулы [4, 10 и др.]. При этом имеющаяся в психологии шкала стрессоров Холмса-Рея, включающая стандартные значимые потрясения, служащие триггером психогений, психосоматозов, составленная на англоязычном материале, не учитывает индивидуализированного набора ежедневных "микротравм" [7], воздействующих не менее весомо.

Цель: разработка методики выявления ранней предрасположенности к психосоматозам по лингвистическим проявлениям и особенностям реакции микрососудистого русла в ответ на предъявление аудиовизуальных стимулов (на группе условно здоровых респондентов возраста юности).

Методика: В 2010 - 2013 гг. со студентами Смоленской государственной медицинской академии (более 300 респондентов) под руководством автора работы проведен предварительный комплекс мероприятий, позволяющих оценить особенности личностного стиля и содержания письменной речи респондентов, выявить набор эмоционально-значимых ситуаций - стрессоров в соотнесенности с психологическим профилем личности (по результатам 
психодиагностических методик, включенных в комплекты MMPI 3.0 и WAIS 2.0. (лаборатория «PSYCOM»)), выявить неконтролируемые физиологические реакции респондента в ответ на предъявление индивидуальных значимых стрессоров.

1-й этап. Было предложено в стандартных условиям (лист бумаги белый, формат А 4, время - 15 минут, до и после занятия) записать значимую историю из жизни при соответствующей предваряющей установке и соблюдении анонимности.

Методика филологического анализа текстов включала этапы: 1. Тематическая организация: минимальные темы (все слова, относимые к значимым частям речи); сюжетные темы; основная тема.

2. Лексико-семантическая организация: лексические, корневые, смысловые повторы (синонимические соответствия); антонимические соответствия; представленность в тексте слов с некоторыми (прочими) типами лексических значений: а) слов с прямыми и переносными значениями, б) однозначных и многозначных слов, в) общеупотребительных слов и слов ограниченной сферы употребления (диалектизмов, терминологической и профессиональной лексики, жаргонной и арготической лексики); г) нейтральной и оценочной, экспрессивной лексики.

3. Грамматическая (морфолого-синтаксическая) организация.

3.1. Морфологические признаки лексики текста.

3.1.1. Представленность в тексте слов разных частей речи: существительных (конкретных, вещественных, абстрактных, собирательных); прилагательных (качественных, относительных, притяжательных; прилагательных в сравнительной и превосходной степени); числительных (количественных, дробных, собирательных, порядковых); местоимений (личных, возвратных, притяжательных, указательных, вопросительных, относительных, отрицательных, неопределенных, определительных); глаголов (совершенного и несовершенного вида; действительного и страдательного залога; 
изъявительного, сослагательного, повелительного наклонения; настоящего, прошедшего, будущего времени; форм 1-го, 2-го, 3-го лица; безличных; причастий и деепричастий); наречий (определительных - со значением качества, количества, способа совершения действия; обстоятельственных - выражающих временные, пространственные, причинные, целевые обстоятельства; в том числе местоименных) и слов категории состояния; служебных частей речи (предлогов, союзов, частиц, междометий; см: разные значения); модальных слов.

3.1.2. Соотношение слов разных частей речи, преобладание в тексте слов определенной части речи.

3.2. Синтаксические признаки текста: представленность в тексте предложений разных типов: а) по цели высказывания - повествовательных, вопросительных, восклицательных; б) разных референциальных типов предложений; в) по структуре - распространенных / нераспространенных; осложненных (однородными членами, обособленными оборотами, вводными словами и предложениями, вставными конструкциями, обращениями); полных / неполных, нечленимых; односоставных (определенно-личных, неопределенноличных, обобщенно-личных, безличных, инфинитивных, номинативных) / двусоставных, с прямым порядком слов / с обратным порядком слов; простых / сложных (сложносочиненных, сложноподчиненных, бессоюзных предложений, сложных синтаксических конструкций); с прямой, косвенной и несобственнопрямой речью.

4. Нарративная организация текстов [6].

4.1. Тип текста: повествование, описание, рассуждение. (дополнительный классификационный признак - преобладание слов определенных частей речи).

4.2. Пространственная и временная организация.

4.2.1. По количеству временных (и/или пространственных) планов: используется один временной (и/или пространственный) план; используется несколько временных (и/или пространственных) планов.

4.2.2. По времени, к которому отнесены повествуемые события. 
4.3. Организация системы нарративных инстанций: Каков образ повествователя (рассказчика)? Кто выступает в роли персонажей и в какими средствами образы персонажей

описаны?

4.4. Организация системы повествовательных точек зрения.

2-й этап. Производились сбор и обработка стандартных анкет эмоциональных стимулов. На титульной стороне листа: «Напишите слова или словосочетания, которые ассоциируются у Вас с положительными эмоциями, вызывают радость, улыбку, приятные чувства и т.д. (50 пронумерованных строк), с негативными эмоциями, вызывают раздражение, агрессию, огорчают и т.д. (50 пронумерованных строк). По возможности заполните пожалуйста все строки. По окончании записи пометьте строки, наиболее значимые для Вас». На обороте листа: «Попробуйте сконцентрироваться и написать слова, которые не вызывают у Вас эмоций, оставляют Вас абсолютно равнодушными, не влияют на расположение духа (постарайтесь пожалуйста назвать не менее 10 слов)».

3-й этап. Испытуемые приглашались для психодиагностики: MMPI 2 и тест К. Леонгарда (Комплект компьютерной психодиагностики MМРI 3.0, www.mmpi.ru).

4-й этап. Была произведена запись лазерной доплеровской флуориметрии поверхностных микрокапилляров [1] (ЛАКК-02) в ответ на предъявление значимых вербальных эмоционально окрашенных стимулов по анкетам.

Результаты: Собраны записи 223 историй. Выявлены группы историй по темам и общей нарративной организации: 1) о проблемных взаимоотношениях (37 экз. текстов), 2) случаи алекситимии («не о чем писать») (26), 3) о причине выбора профессии (22), 4) случаи гиперлекситимии (фрагменты нескольких историй) (косвенно свидетельствуют о потребности в творческом самовыражении, специфике профиля личности или «правополушарности» респондента) (17), 5) о смерти близкого (13), 6) о животных (12), 7) о поступке, по поводу которого респондент испытывает сожаление, стыд (12), 8) о несчастном случае («взрослая» жизнь) (12), 9) о влюбленности (10), 10) о 
неприятности у других людей $(9), 11)$ эпизод витальной угрозы (в детстве) (9), 12) о близких («счастье, что они есть») (8), 13) об удачном случае $(6), 14)$ о путешествиях, отдыхе $(5), 15)$ описание праздника $(5), 16)$ нейтральный случай в детстве (5), 17) о переезде в другой город (3), 18) юмористическая история (2), 19) эмоциональный отклик на события в обществе (2), 20) рисунок (2), 21) парные контрастные по эмоциям истории (1) и др. Типы точки зрения в текстах (по анализу выбора языковых средств, присущих идиостилю респондента или отклоняющихся от него): а) единая точка зрения; б) внутренний конфликт (присутствие антонимов, противопоставленных семантических групп лексики), но не выделены «чужие» точки зрения; в) присутствует ряд точек зрения, выраженных эксплицитно (указан субъект «чужой» точки зрения); г) присутствует ряд точек зрения, но эксплицитно (объект заимствования точки зрения, интроекта по Ф.Перлзу, не назван) выражены не все из них (рассказчик заимствует чужую фразеологию, рассказывает «с чужих слов» о времени раннего детства, но не обозначает факт пересказа и т.п.). По времени повествуемых событий тексты образуют группы: 1) раннее (дошкольное) детство; 2) школьные годы: начальная и средняя школа; 3) старшие классы; 4) период окончания школы; 5) время учебы в институте.

Получены заполненными 65 анкет. Микростимулы классифицированы по 19 семантическим группам: пища; семья; взаимоотношения; хобби: искусство и спорт; деньги; процесс познания; природные факторы и явления; эмоции, переживания; здоровье; вещи, предметы; 11) социум, социальные явления; территория (местность, смена обстановки), ощущения (анализаторы), качества (черты характера, привычки, поведение); время (даты, события); люди (окружение, персонажи); цели и желания; действия (не взаимоотношения); слова и выражения языка. Составлен частотный словарь (общий) микрострессоров и стрессоров в связи со знаком эмоции. Положительные эмоции вызывают: море 43 , любовь 39 , лето 34 , Новый год 32 , солнце 31 , музыка 30, подарки 29 , друзья 27, шоколад 24, цветы 23, мама 23, праздники 22, семья 22, дом 21, мороженое 
21, День Рождения 21, снег 20, путешествие 18, каникулы 17, дети 17, тепло 14, танцы 13 , школа 13 , отдых 12 , сон 12 , поцелуй 11 , улыбка 11 , закат 11 , смех 11 , выходной 11 , папа 11 , фотографии 10 , торт 10 , весна 10 , книги 10 , детство 10 , радуга 10, конфеты 9, телефон 9, интернет 9, комедия 9, свадьба 9, собака 9, каток 8 , дружба 8 , брат 8 , животные 8 , звезды 8 , елка 8 , солнышко 8 , сестра 8 , кофе 8 , сладкое 8 , дискотека 8 , машины 8 , родители 8 , костер 7 , сюрприз 7 , пляж 7, секс 7, мультики 7, лес 7, плед 7, массаж 7, кино 7, свобода 7, зима 7, Париж 7, звездное небо 6, победа 6 , родственники 6 , выпускной 6 , вкусная еда 6 , еда 6 , фильм 6, природа 6 , прогулка 6 , коньки 6 , шопинг 6, песок 6, магазины 6, любимый человек 6 , кошка 6 , подруга 6 , ночь 6 , санки 5 , свет 5 , салют 5 , рыбалка 5 , украшение 5 , забота 5 , радость 5 , ветер 5 , прогулки 5 , поле 5 , счастье 5 , скорость 5, сказки 5, Петербург 5, деньги 5, ребенок 5, сладкая вата 5, шашлыки 5, шарики 5, котенок 5 , апельсин 5, небо 5, луна 5, мандарины 5 , клубника 5, концерт 5, компьютер 5, мотоцикл 5, мультфильмы 5, хорошая погода 5, кинотеатр 5, нежность 5, футбол 5, кровать 5, гитара 4, походы 4, игра 4 , качели 4, игрушки 4, кафе 4, удача 4, анекдот 4, котята 4, дождь 4, СГМА 4, вера 4, велосипед 4, горка 4, доброта 4, вода 4, воздушные шарики 4, спорт 4, мягкие игрушки 4, учеба 4, банан 4, карусель 4, какао 4, лыжи 4, ласка 4, поездка домой 4 , лошади 4 , уют 4 , поезд 4 , понимание 4 , успех 4, «В контакте» 4 , сердце 4, мороз 4. Негативные эмоции вызывают: болезнь 35, смерть 29, предательство 25 , война 22 , ложь 21 , ссора 21 , слезы 20 , алкоголь 18 , холод 18 , одиночество 16 , боль 16, дождь 15 , грязь 14, сессия 14, измена 13, страх 12, наркотики 12 , очередь 11 , авария 11 , слякоть 11 , пожар 11 , несправедливость 10 , курение 10 , расставание 10 , разлука 10 , осень 10 , злость 10 , вранье 10 , темнота 10 , лицемерие 10 , обман 9, больница 9, лень 9, гроза 9, экзамен 8 , депрессия 8 , зависть 8 , глупость 8 , драка 8 , экзамены 8 , наглость 8 , армия 8 , непонимание 8 , грубость 7, змея 7, насилие 7, обида 7 , будильник 7 , убийство 7 , отработки 7 , пауки 7, горе 7, аборт 6, комары 6, усталость 6, кровь 6, голод 6, крик 6, оскорбление 6 , эгоизм 6 , унижение 6 , вонь 5 , мусор 5 , дом 5 , неудача 5 , 
высокомерие 5, гистология 5, утро 5, спор 5, зачет 5, тюрьма 5, лесть 5, ненависть 5, метель 5, хамство 5, печаль 5, кладбище 5, огонь 5, скука 5, потеря 5, ревность 4, рано вставать 4, грусть 4, университет 4, бомж 4, зима 4, соседи 4, старость 4, жадность 4, бессонница 4, беспомощность 4, наркомания 4, черви 4, плохая оценка 4, таракан 4, равнодушие 4, разочарование 4, школа 4, пьянство 4, прыщи 4, маршрутки 4.

Осуществлена запись ЛДФ-граммы 25 испытуемых (10 минут, верхняя треть правого предплечья, с удержанием световода левой рукой испытуемого) при вербальной стимуляции (с интервалом предъявления стимула 10-30 секунд). Самостоятельная поддержка световода испытуемым дает возможность реализовать вариант сопряженной моторной методики А.Р.Лурии [4] и выявить респондентов, в качестве реакции на стимул дающих не изменение показателей микроциркуляции, а тремор левой руки.

\section{Обсуждение и выводы:}

1. Темы письменных и устных историй, созданных в режиме ограничения во времени, в стандартных условиях, без правки, представляют вариант шкалы стрессоров для возрастной и культурной групп.

2. Строение текста историй при анализе коррелирует с данными по шкалам психодиагностических опросников. Например, описание ситуации витальной угрозы (девушка тонет) с парадоксальной реакцией, множественной сменой точек зрения и идентификацией респондентки с ее более умелым братом, по шкалам Миннесотского многофакторного личностного опросника коррелирует с маскулинностью (80) и шизоидностью (73). Описание ситуации обмана респондентом близких в детстве в виде уклонения от послеобеденного сна коррелирует с показателями акцентуированности по опроснику К.Леонгарда (возбудимость - 21, гипертимность - 18).

3. Набор позитивных стимулов в анкетах представляет собой личностное отражение пирамиды потребностей по А.Маслоу [5]. Набор и 
негативных, и позитивных стимулов может являться прообразом шкалы стрессоров и микрострессоров для рассматриваемого возраста и уровня интеллекта.

4. В ходе анализа анкет было выделено 3 группы: 1) косвенные указания на состояние субдепрессии у значительной группы студентов (анкеты с существенным преобладанием негативных стимулов); 2) косвенные указания на запрет негативных эмоций (анкеты с количеством негативных стимулов, в 2-3 раза меньшим по сравнением с числом позитивных стимулов); 3) указания на алекситимию (анкеты с минимальным числом заполненных строк по двум группам стимулов).

5. При отсутствии одной из форм потребностей в наборе позитивных стимулов (или при наличии большого числа обозначений данных стимулов среди негативных) может идти речь о фрустрированности или депревации потребностей данного уровня. В случае наличия слов той же семантической группы и в разделе позитивные, и в разделе негативные стимулы, очевидно, мы можем говорить о наличии неразрешенного конфликта в сфере ее реализации.

6. Если по анкетам эмоциональных стимулов подтверждена тенденция на запрет выражения негативных эмоций, то сделанные записи ЛДФграммы свидетельствуют об общей большей чувствительности к негативной стимуляции.

7. Отсутствие реакции при записи ЛДФ наблюдалось на обобщенные наименования понятий и абстрактную лексику; пиковые реакции наблюдались при наличии индивидуального стимула, представленного конкретным существительным или словосочетанием; наибольшую реакцию вызывали индивидуальные стрессоры, понятные только испытуемому (в том числе амбивалинтные реакции).

8. В зависимости от особенностей реакций на микрострессоры микроциркуляторного русла выделяются группы: 1) испытуемые с 
низкой лабильностью нервных процессов $(\mathrm{Kv}<10) ; 2)$ испытуемые со склонностью к соматизации эмоциональных переживаний (выраженная вегетативная реакция на стимул: $10<\mathrm{Kv}<20$ (в отдельных случаях - и более), запись без артефактов); присутствуют выраженная тенденции к формированию «коронарной личности»; 3) испытуемые с моторной реакцией на эмоциональный раздражитель при относительной устойчивости показателей микроциркуляции (запись с артефактами: выраженная экстрапирамидная реакция на стимул, тремор, падение изолинии до 0: Kv > 20); в терминологии Ф.Данбар, «личность, склонная к повреждениям».

Заключение: описанная выше междисциплинарная методика, прошедшая в данном эксперименте этап первичной верификации, может быть полезна для реализации профилактического подхода в медицине, для выявления личностного набора эмоциональных стрессогенных стимулов условно здоровых респондентов (и пациентов с определенной патологией), для предотвращения закрепления патологических эмоциональных реакций в ответ на повторное предъявление стрессирующих факторов. Важную роль методика может сыграть в изучении личности художника (автора произведений культуры).

По материалам анкет разработан и активно используется в диагностике универсальный набор визуальных стимулов (50 кадров, слайд-шоу с настраиваемым временем предъявления) для фиксации ответа на микрострессоры посредством записи лазерной допплеровской флоуметрии микрокапилляров респондента. Результатом исследования стала разработка методики экспертизы письменного текста респондента от руки на наличие личностных травмирующих стрессоров, с целью постановки диагноза клиническим психологом и последующей эффективной психотерапии. 


\section{Литература:}

1. Лазерная допплеровская флуориметрия микроциркуляции крови / Под редакцией А.И. Крупаткина, В.В. Сидорова. - М., 2005.

2. Леонгард К. Акцентуированные личности // Психология индивидуальных различий. - М., 2000. - С. 585-663.

3. Леонтьев А.А. Психолингвистические единицы и порождение речевого высказывания. М.: УРСС, 2003. С. 178.

4. Лурия А.Р. Психологическое наследие. - М., 2003.

5. Маслоу А. Мотивация и личность. - СПб., 2002.

6. Падучева Е.В. Семантические исследования: Семантика нарратива. - М., 1996.

7. Пезешкиан Н. Психосоматика и позитивная психотерапия. - М.,2006.

8. Петренко В.Ф. Основы психосемантики. 2-е изд. - М., 2005.

9. Сикевич 3.В., Крокинской О.К., Поссель Ю.А. Социальное бессознательное. - М.; СПб., 2006.

10. Хризман Т.П., Еремеева В.Д., Лоскутова Т.Д. Эмоции, речь и активность мозга ребенка. - М., 1991. 